\title{
IMPLANTAÇÃO DE MICRO MOBILIDADE URBANA ATRAVÉS DAS PATINETES ELÉTRICAS NO MUNICÍPIO DE SÃO JOSÉ DOS CAMPOS/SP COMO LOGÍSTICA FLEXÍVEL DE LOCOMOÇÃO
}

\author{
L. L. A. Raposo ${ }^{1,}$; R. A. Moura ${ }^{1}$ \\ 1 Faculdade de Tecnologia de São José dos Campos - Professor Jessen Vidal \\ Av. Cesare Mansueto Giulio Lattes, 1350 - Eugênio de Melo, São José dos Campos/SP, \\ CEP: 12247-014, Brasil. \\ Telefone: (12) 3905-2423 \\ *lestsjcamorim@gmail.com
}

\begin{abstract}
RESUMO: O aumento expressivo de veículos e a falta de infraestrutura capaz de evitar congestionamentos no trânsito urbano, forçou as cidades a adotarem estratégias e uso da micro mobilidade que inclui veículos como as patinetes e bicicletas. A micro mobilidade é prática, sustentável e flexível para deslocamentos em curtos trajetos urbanos, que muitas vezes são percorridos a pé ou por outro tipo de condução. Este trabalho objetiva demonstrar que a implantação das patinetes em adição as bicicletas, pode ser uma alternativa de mobilidade urbana. O método adotado inclui uma pesquisa bibliográfica, seguida de uma entrevista a 356 voluntários de ambos os sexos que responderam três perguntas distintas. Os resultados demonstraram a preferência por transportes público $(50,8 \%)$, uso de patinetes como meio de locomoção $(78,9 \%)$ e que a maior parte dos entrevistados consideram a patinete como micro mobilidade $(45,8 \%)$.
\end{abstract}

PALAVRAS-CHAVE: patinetes; mobilidade; micro mobilidade.

\begin{abstract}
The significant increase in vehicles and the lack of infrastructure capable of avoiding congestion in urban traffic has forced cities to adopt strategies and use of micro mobility that includes vehicles such as scooters and bicycles. Micro mobility is practical, sustainable and flexible for commuting on short urban journeys that are often traveled on foot or by other types of driving. This paper aims to demonstrate that the implementation of scooters in addition to bicycles can be an alternative of urban mobility. The method adopted includes a literature search, followed by an interview with 356 volunteers of both sexes who answered three distinct questions. The results showed a preference for public transportation (50.8\%), using scooters as form of locomotion (78.9\%) and that most respondents consider the scooter as micro mobility (45.8\%).
\end{abstract}

KEYWORDS: scooters; mobility; micro mobility

\section{INTRODUÇÃO}

Com uma atitude inovadora diferente para o meio de locomoção, as patinetes elétricas ou não, se tornaram uma proposta de locomoção nas vias públicas da cidade de São José dos Campos/SP. O costume de se utilizar automóveis para se deslocar no centro e em outros pontos da cidade tem sido um dos motivos de congestionamentos. Nesse sentido as bicicletas e as patinetes compartilhadas vêm ganhando espaço e dividindo lugar nas ciclovias e ciclo faixas por determinação, que deve ser observada pelas empresas responsáveis. 
Na Figura 1, um exemplo de patinetes e bicicletas compartilhadas.

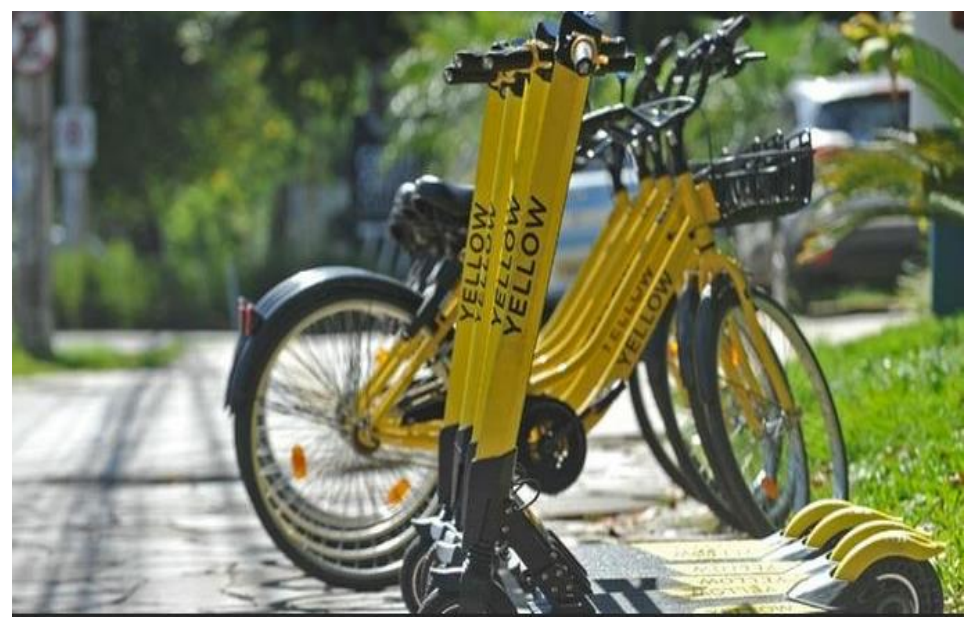

Figura 1. Patinete e bicicletas para micro mobilidade

De forma útil e simples, sua utilização proporciona também reviver a infância e juventude em seus usuários, juntamente despertando a curiosidade dos mais novos. Podemos dizer que o uso das patinetes é visto como uma logística flexível, que foi a resposta mais rápida criada por startups para as grandes dificuldades de se transitar no dia a dia em vias completas.

A mobilidade urbana para os dias de hoje deve se adaptar para receber modais como as patinetes, e a sua ascensão depende do uso e funcionamento correto nos centros urbanos, como por exemplo o uso de capacetes. Segundo o Ministério das Cidades (2005), implantar meios de locomoção inteligentes, pode ser definido em ações que região com potencial de investimentos e qualidade de vida para seus habitantes. Exercitando uma conexão que ultrapasse barreiras, a mobilidade urbana deve abranger o desenvolvimento e agregar valorizam uma cidade, uma valores para o crescimento socioeconômico de toda a região. Na Figura 2, um exemplo de uso das patinetes.

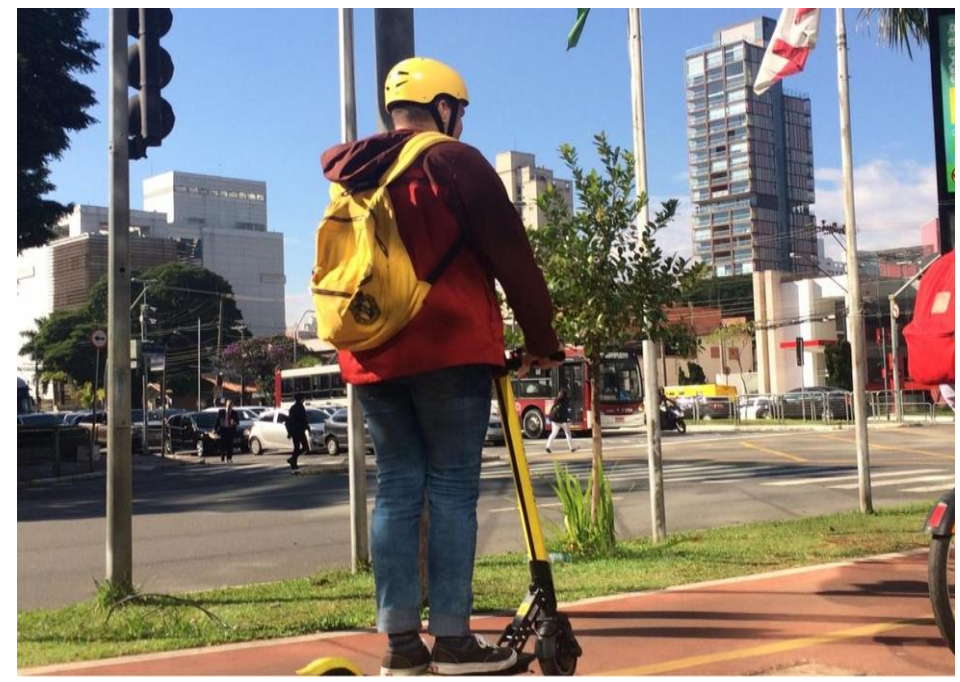

Figura 2. Uso da patinete na locomoção diária.

Segundo a reportagem da Revista Exame, em 15 de abril de 2019, as empresas startups, dentre elas a empresa brasileira Yellow, através de seu diretor, esclarece que o objetivo de divulgar o uso das patinetes, é melhorar a mobilidade e reduzir a emissão de gases que causam o efeito estufa por 
meio de um meio de transporte divertido, eficiente em termos de custo e que se integra com outras formas de locomoção, otimizando a rotina diária em grandes cidades, o que está em linha, que a ideia principal da micro mobilidade é otimizar a locomoção da população ao mesmo tempo dando qualidade de transporte menos poluente (ABRIL, 2019).

\section{REVISÃO DA LITERATURA}

Segundo Amaral (2007), a pesquisa bibliográfica é uma etapa fundamental em todo trabalho científico que influenciará todas as etapas de uma pesquisa, na medida em que der o embasamento teórico do trabalho.

Segundo Santana (2018), de forma descontraída e tímida, a utilização da patinete como meio de transporte entra no gosto das pessoas. A parte polêmica a ser tratada não é o executivo de terno saído do trabalho e indo até um restaurante na hora do almoço- atitude essa cada vez mais comum no cotidiano- mas sim o equipamento utilizado por ele, a patinete. $O$ uso do gênero na palavra pode dificultar mais até que as próprias regras quanto à utilização da patinete e na contramão do emprego cotidiano, os dicionários da Língua Portuguesa (VOLP) registram "patinete" como um substantivo feminino e, portanto, é a patinete (SANTANA, 2018).

\subsection{Mobilidade Urbana}

Mobilidade urbana pode ser definida em ações que valorizam uma cidade, uma região com potencial de investimentos e qualidade de vida para seus habitantes, se conectando para ultrapassar barreiras e abrange o desenvolvimento onde agrega valores para o crescimento socioeconômico (MINISTÉRIO DAS CIDADES, 2005).

A mobilidade urbana está diretamente ligada ao Planejamento Urbano que traz melhorias para a região e auxilia na criação de meios que otimizam o espaço urbano agregando valor para a localidade. O planejamento urbano em países desenvolvidos é diferenciado de países subdesenvolvidos. $\mathrm{O}$ transporte urbano e suas implicações têm ampliado esse desafio nas últimas décadas exigindo alterações nos padrões atuais de mobilidade, na promoção de desenvolver um plano de mobilidade sustentável com atrativos nos centros urbanos (SEABRA e TACO, 2013).

\subsection{Micro mobilidade urbana}

Segundo Arcon (2019), micro mobilidade significa ações para facilitar o deslocamento de pessoas e bens nas cidades, com o objetivo de impactar positivamente atividades econômicas e sociais no perímetro urbano de uma cidade. A primeira aparição do termo micro mobilidade foi em 2017 sendo uma nova alternativa de veículos inseridos nas cidades seguindo os seguintes critérios, até 500 $\mathrm{kg}$, acionamento elétrico e utilização como meio de transporte ou locomoção urbana.

Ainda segundo Arcon (2019), a micro mobilidade urbana é impactada positivamente pela economia compartilhada. Algumas empresas oferecem ajuda de custo para quem optar por fazer o recolhimento e a recarga da bateria das patinetes, desde que respeitado a restrição no horário de recolocação no ponto de uso e nesse viés, o CONTRAN que é o Conselho Nacional de Trânsito, vem elaborando diretrizes e regras para o uso das patinetes como veículos de locomoção.

O Jornal a Folha de São Paulo, no mês de maio de 2019, divulgou uma nota que a Prefeitura de São Paulo, anunciou uma regulamentação provisória para desempenho eficiente das patinetes na cidade e a forma em que o usuário deve usar a patinete, conforme o Decreto $\mathrm{n}^{\mathbf{0} 58.750}$ de 2019, obrigando o uso de capacete, proibindo a circulação nas calçadas e limitando a velocidade em ciclovias, ciclo faixas e ciclorrotas de no máximo $40 \mathrm{~km} / \mathrm{h}$ e informou ainda que a fiscalização e 
auditorias ficariam sob a responsabilidade das autoridades de trânsito como a Guarda Civil Municipal e agentes das Subprefeituras (JORNAL A FOLHA, 2019).

A regulamentação proporciona um aspecto de segurança e garantia para aqueles que desconhecem ou temem desfrutar das patinetes, alertando que se deve ter precaução e responsabilidade na hora de utilizar a patinete (CONTRAN, 2019).

Essa visão de um mundo em desenvolvimento utilizando da tecnologia afeta diretamente todos com um grande leque de possibilidades como, em tempos de crise, cria-se oportunidades que geralmente são ideias completamente diferente, baseando-se nisso, empresas em atuação no Brasil, como a Yellow e a Grin que criaram o perfil profissional chamados charges, pessoas que se cadastram no aplicativo e executam o trabalho de recolher, carregar e distribuir as patinetes nos pontos de uso conforme indicados pelas empresas em seus aplicativos. A pessoa cadastrada é remunerada a partir do momento em que entregas as patinetes carregadas no ponto de uso indicado pelas empresas (GAÚCHAZH, 2019). Na Figura 3, um exemplo de charges.

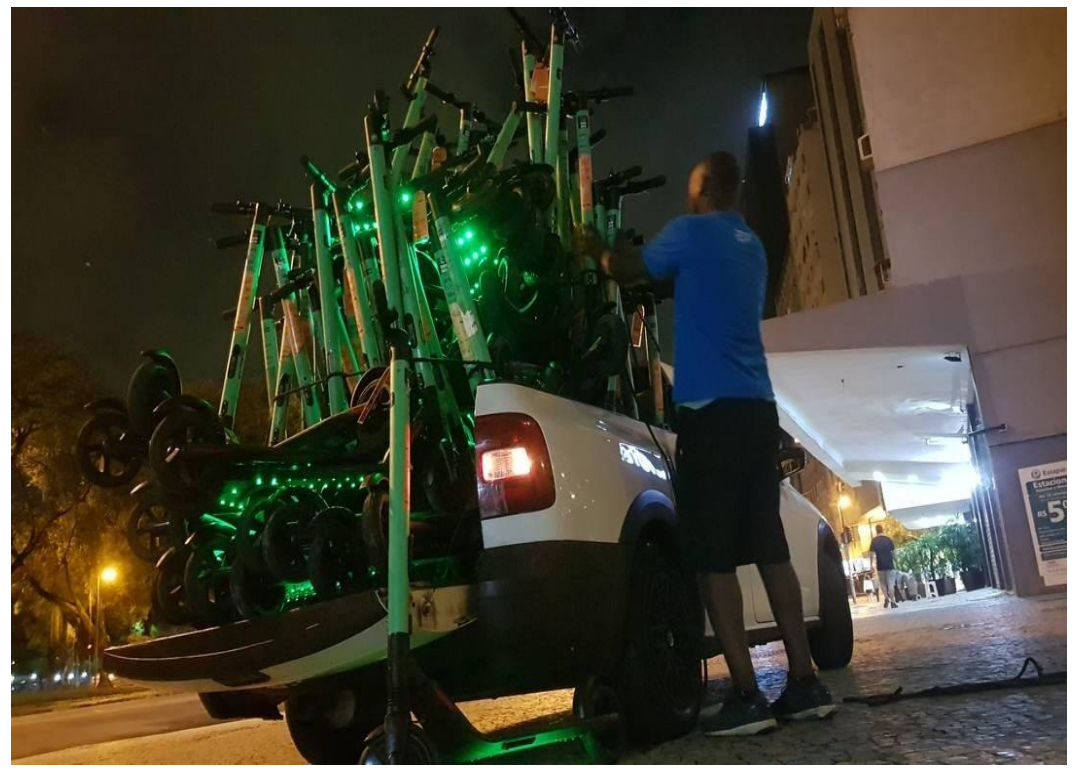

Figura 3. Charger preparando a patinete para um novo ciclo de locomoção

Em uma hipótese remota e assertiva, uma nova profissão surgiu e um novo perfil profissional, garantirá os níveis de empregabilidade, no qual a rentabilidade que esse trabalho proporciona fará diferença para quem está desempregado, sendo um tipo de trabalho alternativo e popular em todo o território nacional (GAÚCHAZH, 2019).

\section{MATERIAIS E MÉTODOS}

Primeiramente foi feito uma pesquisa bibliográfica e em seguida uma pesquisa com coleta de dados amostral da população de 4.000 cidadãos que vivem na região leste sobre o uso ou não das patinetes como meio de locomoção individual.

A pesquisa foi inserida na plataforma Formulários do Google tendo sua disseminação nas redes sociais para coleta de dados.

Em seguida, adotou-se a uma metodologia dividida em quatro etapas.

$\checkmark$ Na primeira etapa, a elaboração do tema de abordagem.

$\checkmark$ A segunda etapa, aborda uma pesquisa amostral qualitativa e quantitativa;

$\checkmark$ Terceira etapa, a divulgação e, 
$\checkmark$ Na quarta análise e discussão dos resultados.

O contexto desta pesquisa está estruturado de forma aplicada com o objetivo de gerar conhecimentos para aplicação prática dirigida à solução de problemas de locomoção que envolve verdades, peculiaridades e interesses locais (MORESI, 2003).

No desenvolvimento deste trabalho optou-se pelo conhecimento exploratório a fim de conhecer e integrar meios sustentáveis na mobilidade urbana na região da cidade de São José dos Campos/SP, durante os meses de junho e julho de 2019, oportunidade em que foram ouvidos e registrados a opinião de 356 voluntários de ambos os sexos com faixa etária de 18 a 60 anos.

\subsection{Cálculo do número de amostra e margem de erro}

Segundo Triola (2008), como na maioria das vezes é inviável ouvir a opinião de toda uma população ou avaliar todos os produtos de uma linha de montagem, podemos analisar uma amostra e fazer inferências sobre o todo, pois a amostra representa o todo desde que, realizada de forma aleatória. Estatisticamente, há uma relação direta entre proporção da amostra e a margem de erro.

O tamanho da amostra pode ser calculado utilizando a Equação 1.

$$
\mathrm{n}=\frac{N \cdot Z^{2} \cdot p \cdot(1-p)}{(N-1) \cdot \mathrm{e}^{2}+Z^{2} \cdot p \cdot(1-p)}
$$

Onde:

$\mathbf{n}=$ tamanho da amostra;

$\mathbf{N}=$ tamanho da população;

$\mathbf{Z}=$ desvio do valor médio;

$\mathbf{e}=$ margem de erro;

$\boldsymbol{p}=$ "Rô". Proporção da pesquisa.

A margem de erro representa quantos pontos percentuais às respostas da sua população irão variar em relação às respostas obtidas com a amostra. Quanto menor a margem de erro, mais próximo se estará da resposta exata a um grau de confiança específico (LEVIN, 2004).

Substituindo na equação 1 , tem-se:

População (região leste) $\quad=4.000$ indivíduos

Tamanho da amostra $\quad=356$ indivíduos.

Confiabilidade $\quad=95 \%$.

Margem de erro $\quad=5 \%$.

\subsection{Protocolo da pesquisa e objetivos das perguntas}

Foram realizadas três perguntas e obtidas respostas de 356 comensais de forma aleatória para ambos os sexos. Como forma de consolidar o presente trabalho, foi elaborado um questionário para a população em geral sem restrições de localidade, idade e sexo. O questionário foi realizado no mês de junho e julho de 2019 entre os dias 01/06/2019 à 31/07/2019.

Com as respostas obtidas, cria-se um cenário em que as patinetes elétricas podem ser consideradas um meio de transporte sustentável. Que na qual auxilia diretamente no modo de locomoção de todos. A implantação das bicicletas e patinetes elétricas trouxe para as cidades um desenvolvimento que muitos enxergam e acreditam que apenas em outros países é possível.

Para muitos, a tecnologia de cidades futurísticas são somente um sonho de consumo inalcançável e inacessível em uma país como o Brasil, temos um grande potencial para nos igualar a grandes países. Na Figura 4, o questionário aplicado amostral mente e de forma aleatória para a população da região leste da cidade de São José dos Campos/SP. 


\section{Pesquisa Logística sobre a Mobilidade Urbana}

*Obrigatório

Você utiliza qual meio de mobilidade urbana? *

Publico

Privado

Você concorda que a patinete pode ser considerada como micro mobilidade urbana? *

Sim

Não

Você se locomoveria de um lugar para outro na cidade através da micro mobilidade? *

\section{Sim}

Não

Considero o uso da patinete como micro mobilidade que eu usaria.

Figura 4. Questionário aplicado para população.

\section{RESULTADOS E DISCUSSÕES}

A primeira questão abordada apresenta a forma utilizada como meio de transporte para se locomover. De acordo com as respostas dadas, podemos ter a informação de que muitos utilizam o transporte público como meio de transporte a optar pelo veículo particular. Para a grande maioria da população os custos são de maior importância na hora de escolher o meio de locomoção. A preferência pelo transporte particular vai muito além de custo, conforme demonstra o Gráfico 1. 


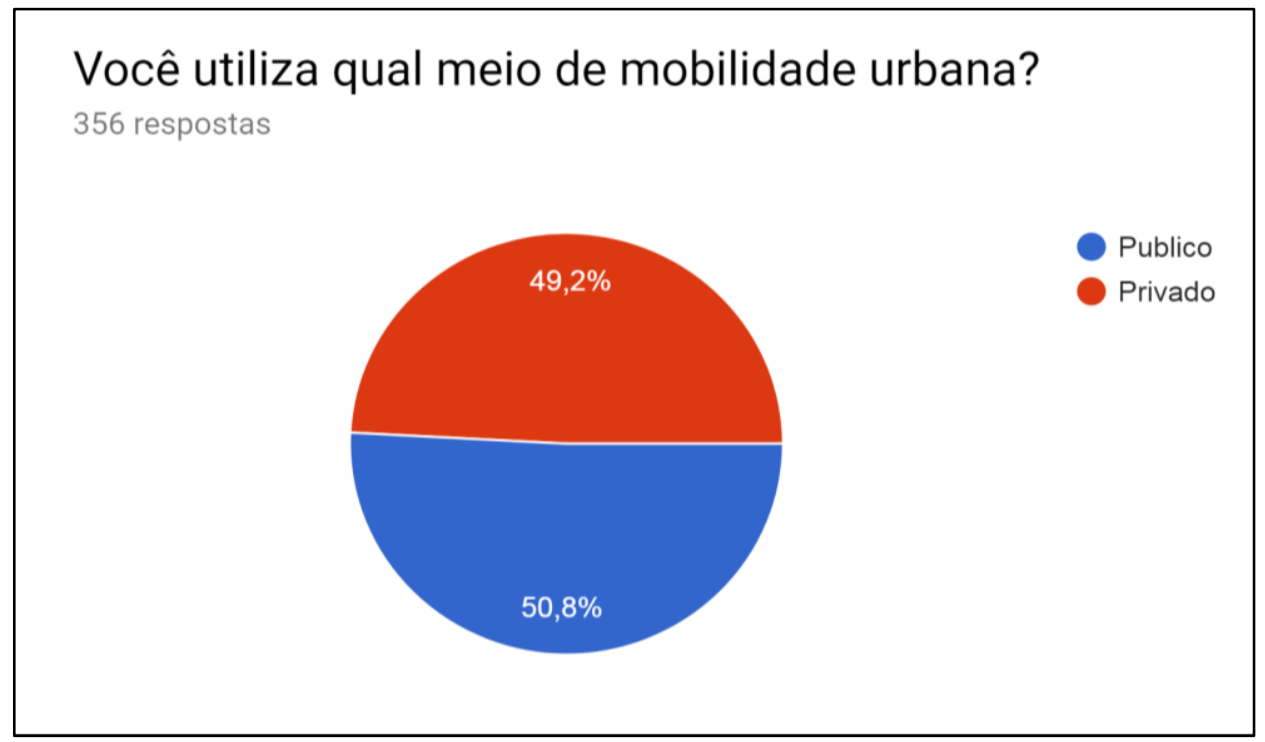

Gráfico 1. Primeira questão do questionário

Os resultados obtidos apresentam uma visão que não é diferente 49,2\% utiliza o transporte público como meio de locomoção e o privado fica com 50,8\%, como mostra os dados do Gráfico 1.

O Gráfico 2 apresenta a visão que as pessoas têm do uso das patinetes, aliás com valores de locação acessíveis para maior parte da população se comparado a veículos maiores.

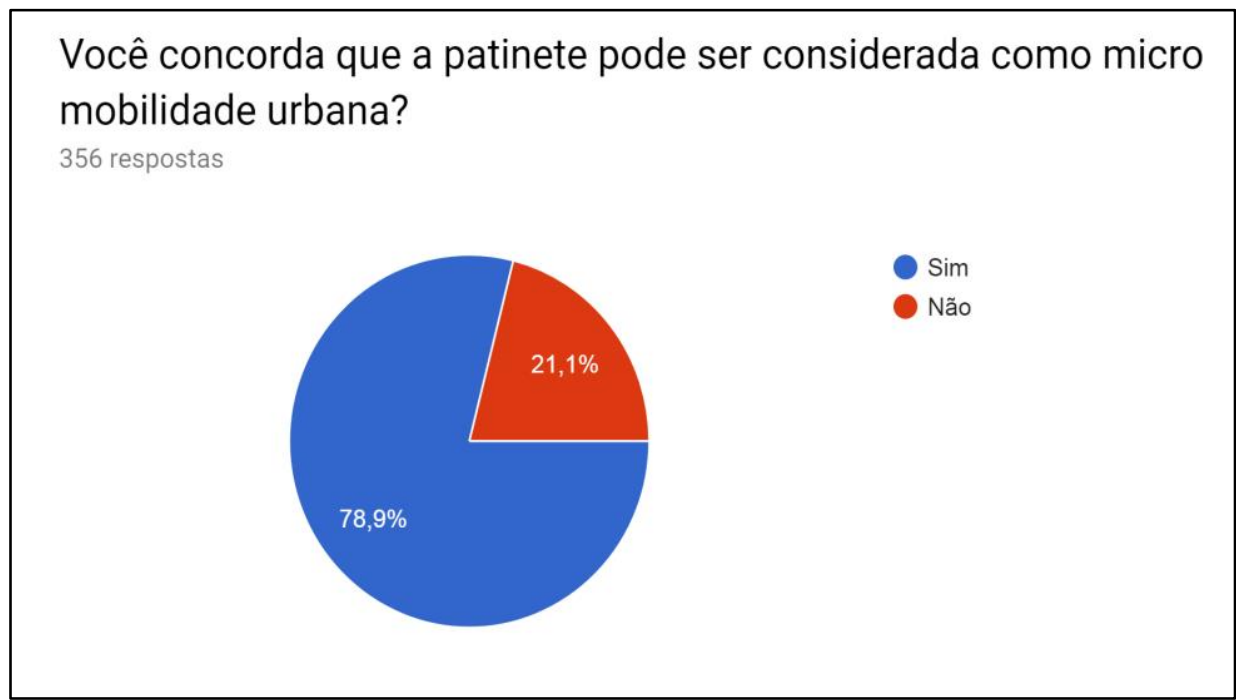

Gráfico 2. Segunda questão do questionário

Para a segunda questão, levamos em conta a falta de informação das pessoas em relação ao conhecimento de saber o que é e como funciona a micro mobilidade, podendo levar muitos a ter um preconceito formado sem a devida informação.

As notícias que circulam de forma negativa com as patinetes contribuem diretamente com a negação de aceitar que as patinetes são uma forma de micro mobilidade. Sua utilização auxilia no dia a dia das pessoas que optam pelo meio de transporte que visa economia de tempo em determinados horários. 
Na terceira questão temos a variação da particularidade de cada indivíduo entrevistado. Muitos considera utilizar a micro mobilidade para se locomover e outros utilizaria a patinete como apresentado na Gráfico 3.

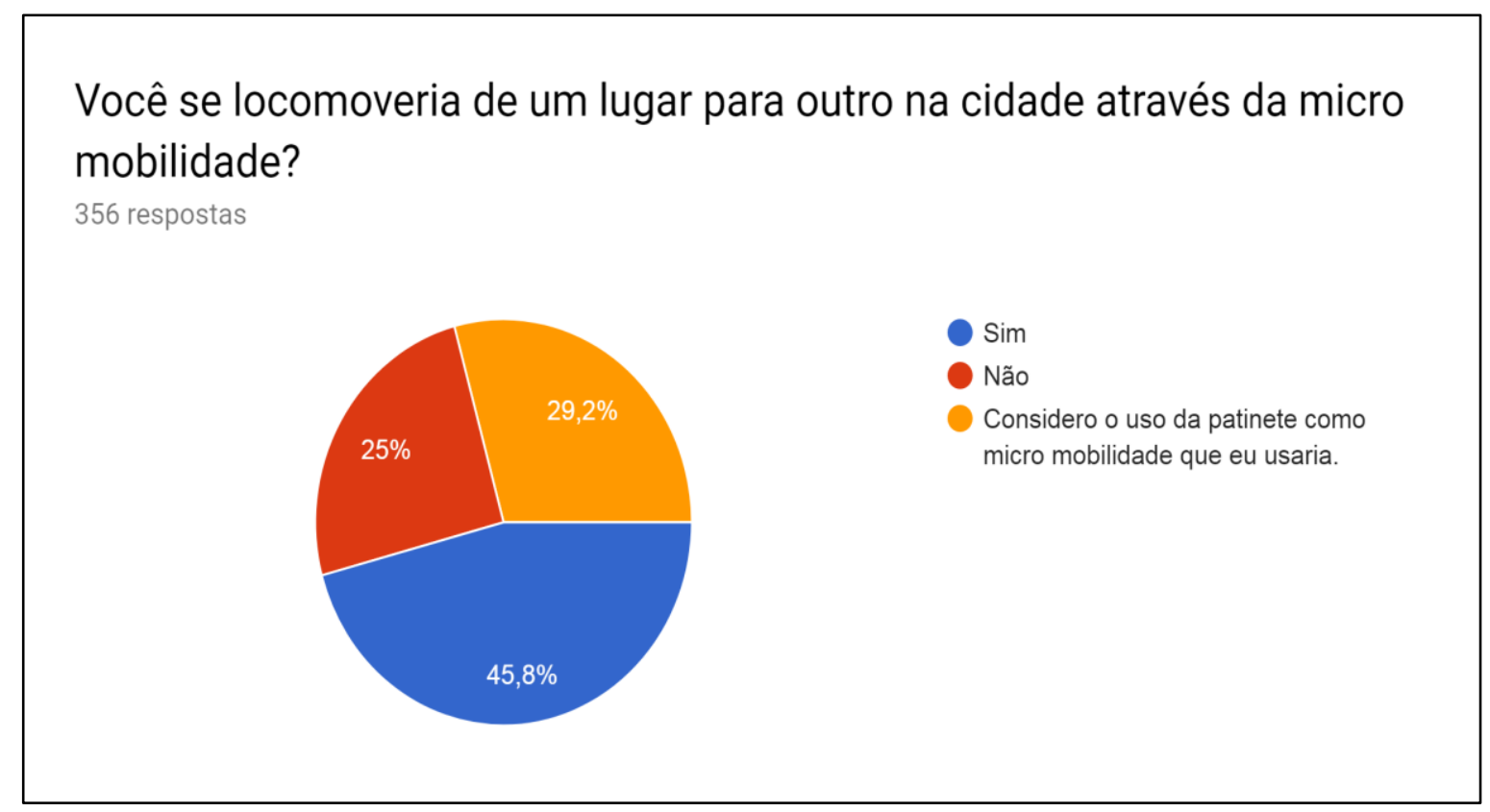

Gráfico 3. Terceira questão apresentada no questionário

Vários fatores podem contribuir para ter $25 \%$ de recusa da modalidade. Os motivos podem ser inúmeros como os custos, a restrição no perímetro de atuação na região, medo de sofre e causar acidentes.

\section{CONCLUSÕES}

A implantação das patinetes independe de critérios como solucionar os grandes congestionamentos, superlotação do transporte público disponibilização de plataformas leves e capazes atender pessoas de várias faixas etárias.

A ideia de utilizar a patinete vai além do lazer, seu aproveitamento inclui pequenas distâncias urbanas como no início da manhã e no final da tarde.

A aprovação de uma legislação pertinente, também é aguardada como por exemplo, leis para o uso dentro do conceito de micro mobilidade.

O bom funcionamento das patinetes como meio de locomoção, depende de diversos fatores, entre eles, a responsabilidade de quem conduz e dos motoristas e pedestres de forma geral.

Os resultados encontrados, para uma população e 4.000 moradores da região leste de São José dos Campos/SP, com uma amostra de 356 entrevistados, permitem um grau de confiança de até $95 \%$ e uma margem de erro de até $5 \%$, apontando que a preferência por transportes público é de 50,8\%, e usariam a patinete como meio de locomoção 78,9 \% dos entrevistados e que quando questionados se consideram a patinete como micro mobilidade, $45,8 \%$ disseram que sim e $29,2 \%$ disseram que tem intenção de usar quando estiverem disponíveis.

Como trabalho futuro, pode-se ampliar o tamanho da amostra. 


\section{REFERÊNCIAS}

ABRIL. Revista semanal. Disponível em: https://exame.abril.com.br/pme/fundadores-da-99-jaestao-de-negocio-novo-e-captaram-r-30-milhoes/ Acesso em:13 jun.2019

ABRIL. Revista semanal. Disponível em: https://exame.abril.com.br/tecnologia/yellow-e-grinjuntas-o-casamento-da-bicicleta-com-o-patinete-eletrico/ Acesso em: 24 de jun.2019

ABRIL. Revista semanal. Disponível em: https://exame.abril.com.br/brasil/74-dos-brasileirosquerem-menos-carro-e-mais-onibus-e-bike/ Acesso em: 26 de jun.2019

ABRIL. Revista semanal. Disponível em: https://exame.abril.com.br/pme/apos-discussao-patinetesgrin-e-yellow-voltarao-a-sp-nesta-quinta-feira/.. Acesso em 28jun.2019.

AMARAL, João J. F. Como fazer uma pesquisa bibliográfica. - Ceará: Universidade Federal do Ceará, 2007. 21 p. Disponível em: http://200.17.137.109:8081/xiscanoe/courses1/mentoring/tutoring/Como\%20fazer\%20pesquisa\%20bibliografica.pdf . Acesso em

ARCON, G.CEO e Co-Founder na @ E-Moving Mobilidade Urbana. Revista Polinize. São Paulo/SP. Brasil. Online. Disponível em: https://polinize.com/o-que-e-micromobilidade-urbana-e-como-elaimpacta-o-cotidiano-das-pessoas/ Acesso em: 24 de jun.2019

BRASIL. Mobilidade pública e urbana. Disponível em: https://www.mobilize.org.br/noticias/10739/ma-qualidade-do-transporte-publico-aumentapreferencia-por-carro.html. Acesso em 28jun.2019.

BRASIL. DECRETO No 58.750 de 13 DE MAIO DE 2019. Dispõe sobre a regulamentação provisória do serviço de compartilhamento e do uso dos equipamentos de mobilidade individual auto propelidos, patinetes, ciclos e similares elétricos ou não, acionados por plataformas digitais. SÃO PAULO, SP, mai,2019, http://legislacao.prefeitura.sp.gov.br/leis/decreto-58750-de-13-de-maio-de$\underline{2019}$. Acesso em 22 de jun.2019.

CONTRAN. Conselho Nacional de Trânsito. LEI No 9.503, DE 23 DE SETEMBRO DE 1997. Disponível em: http://www.planalto.gov.br/ccivil_03/leis/19503.htm. Acesso em:28jun.2019

GAÚCHAZH, Revista Online Semanal. Disponível em: https://gauchazh.clicrbs.com.br/portoalegre/noticia/2019/05/conheca-os-chargers-que-chegam-a-ganhar-mais-de-r-5-mil-para-recolhercarregar-e-devolver-as-patinetes-na-capital-cjw2c0d9x01ix01lbqk6yv4el.html. Acesso em 6 de jul.2019

JORNAL A FOLHA DE SÃO PAULO. Circulação semanal. Disponível em https://www1.folha.uol.com.br/cotidiano/2019/05/covas-obriga-o-uso-de-capacetes-e-proibe-usode-patinetes-nas-calcadas.shtml Acesso em:28jun.2019

JORNAL A FOLHA DE SÃO PAULO. Disponível em: https://www1.folha.uol.com.br/cotidiano/2019/05/na-falta-de-regra-patinetes-e-pedestres-disputamcalcadas-em-sp.shtml Acesso em: 28 de jun.2019 
LEVIN, Jack. Estatística Aplicada a Ciências Humanas. 5a . Ed. Revisada. 2a Reimp. Florianópolis: Editora UFSC, 2004.

MINISTÉRIO DAS CIDADES. Cadernos do Ministério das Cidades. Brasília: MCidades/Governo Federal, 2005

MORESI, E.A.D. Apostila de metodologia da pesquisa. Brasília: Universidade Católica de Brasília, 2003.

PROJETO COLABORA Revista semanal. Disponível em: https://projetocolabora.com.br/mobilidade/a-micromobilidade-avanca-nas-cidades-brasileiras/ Acesso em:13 de jun.2019

SANTANA. E. Vocabulário Oficial da Língua Portuguesa (VOLP). 2018. Disponível em: https://blog.grancursosonline.com.br/o-patinete-ou-a-patinete/. Acesso em: 06 jun.2019.

SEABRA, L. O.; TACO, P. W. G. Mobilidade Urbana no Brasil: antecedentes e perspectivas à luz dos mecanismos de gestão. In: XVIII Congresso Pan-americano de Ingeniería de Tránsito, Transporte y logística (PANAM 2014), 2014, Santander-Espanha. TRANSPORTE INTELIGENTE PARA UN FUTURO SOSTENIBLE, 2014.

TRIOLA, Mário F. Introdução à Estatística. 10ª Ed. Belo Horizonte: LTC, 2008. 